An important event in 1934 was the inaugural meeting of "The Friends of the Curtis Museum", a body which has done much for the Museum and continues to the present day. In 1946, the Museum was transferred to the Hampshire County Council under the terms of the Education Act, 1944. A grant from the Carnegie Trust was announced in 1949, and this helped the Museum to assume the modern aspect which characterizes it at the present day. In 1951 the appointment of a full-time curator brought the Museum into line with so many similar institutions up and down the country. The history concludes with an appreciation by Mr. C. P. Chatwin on the geological work of William Curtis.

This stimulating, almost, year-by-year, record of the vicissitudes of a local museum is of interest not only to the community in Alton but also to the wider museum public, who see in it an epitome of what has'happened at so many centres.

\section{PATHOLOGY OF CANCER}

The Genesis and Prevention of Cancer

Second Edition. By W. Sampson Handley. (London: John Murray (Publishers), Ltd., 1955.) $21 s$.

THE first edition of Mr. W. Sampson Handley's book appeared a quarter of a century ago. Although this new edition has recently been revised, the author's original ideas as to the cause of cancer remain unchanged. Many theories of the causation of malignaney are discussed and discarded. The virus theory is dismissed, and the author predicts "no specific organism of cancer will ever be discovered". Mr. Sampson Handley contends there is a definite correlation between the induction of cancer and lymph-statis. This theory was gradually built up over twenty-five years of elinical and histological study of the disease in all its many manifestations. He marshals evidence for his conclusion that precancerous lesions are areas in which the lymphatic vessels have either been blocked or else obliterated by chronic inflammation or congenital defect. $\mathrm{He}$ further argues that, as lymphatic obstruction always precedes cancer, it is therefore the main factor in causing the disease.

This view, although not universally accepted by pathologists as the cause of cancer, might hold for some types of malignancy. It would be an oversimplification to accept this theory as the universal cause of cancer. For example, it would be difficult to explain the origin of some forms of endocrine cancers, which depend on hormones both for their induction and maintenance, and which regress once the hormonal stimulus is withdrawn. Under such conditions, do accompanying changes first occur in the lymphatics before the onset of the disease, and can they be expected to disappear during regression ? If so, they have not been adequately demonstrated.

Mr. Sampson Handley has done admirable pioneer work on the pathology of breast tumours, and has contributed greatly to our present knowledge of the spread of tumours via the lymphatic pathway. Although many might find his theories controversial, they will also find them stimulating. All who are interested in the histology of the early development of tumours should read this book.

There is also a chapter on cancer prophylaxis. Among the many preventive measures discussed, preputiotomy in children is recommended at birth in order to reduce the incidence of cancer both of the penis and the cervix. In this same chapter, when discussing constitutional factors such as hormones in the etiology of the disease, he contends that they "play only a subordinate part". This attitude is scarcely in accord with modern biological findings.

The book is well illustrated and has an appendix entitled "Tobacco and Cancer", in which some interesting statistics are given concerning lung cancer and other diseases occurring among heavy smokers.

\section{CHROMOSOMES OF HIGHER PLANTS}

\section{Chromosome Botany}

By Prof. C. D. Darlington. Pp. xii + 186. (London : George Allen and Unwin, Ltd., 1956.) 16s, net.

$\mathrm{N}$ this useful little book are summarized the important facts and points of view concerning the chromosome numbers and chromosome morphology of the higher plants (chiefly the Angiosperms), and the significance of their cytology in clarifying the taxonomy, phylogeny, geographical distribution and ultimately the evolution of the plants concerned. The facts and points of view are mainly those which have emerged during the period 1930-56 ; approximately the period since the publication of the first edition of the "Recent Advances in Cytology". Most of the topics dealt with in this epoch-making book have now received a revised treatment from the author in the several volumes written independently or in collaboration with Prof. K. Mather. The present volume brings to a considerable degree of completeness an achievement represented by books which are essentially challenging presentations of facts rather than dispassionate compilations. 'The reviewer does not forget that compilations and a practical hand. book have been provided as well.

$B$-chromosomes, apomixis, microspecies, polyploidy and plant geography, ecological variation, change of basic chromosome number, change of chromosome morphology and chromosome size, centres of diversity, wheat, maize, Rosa, Chrysanthemum, are among the subjects treated, often with useful detail. On certain of them it has long been desirable to be able to quote the author's views. On the whole, these views do not differ markedly from those generally held, although, as always, it would be easy to quote sentences from this author with which few would agree. There are no complex diagrams. The sections dealing with basic numbers are particularly illuminating, although the bold assertion of 1949 in regard to the basic chromosome number of the ancestral Angiosperms is repeated here and their seven chromosomes appear on the dust-cover. Broadly, the book is an elaboration of the introduction to the first edition of the "Chromosome Atlas".

There is a separate bibliography for each chapter; but authors' names are also indexed. One feels that the names of some whose ideas have been assimilated, perhaps subconsciously, should not have been missing, for example, those of Huxley and Turill ; yet, of course, it is an advantage that the size of the volume has been kept down to that which a student can afford to buy. Every serious student of botany should be recommended to purchase this book, the only one of its kind published in Britain. There is an informative little appendix by E. B. Ford, on moths, butterflies and Primula. M. B. E. Godward 